\title{
CIÊNCIA EM DEBATE: UMA ANÁLISE DO GÊNERO NOTÍCIA DE POPULARIZAÇÃO DA CIÊNCIA*
}

\author{
SCIENCE UNDER DEBATE: AN ANALYSIS OF THE SCIENCE POPULARIZATION \\ NEWS GENRE
}

\author{
Patrícia Marcuzzo \\ Universidade Federal de Santa Maria
}

\begin{abstract}
Resumo
Este artigo apresenta uma análise das vozes apresentadas em notícias de popularização da ciência (PC). Foram analisados 30 exemplares de notícias de PC dos sites BBC News e Scientific American a partir da ótica da Análise Crítica do Discurso (VAN LEEUWEN, 1996; 2008). Os resultados indicam que esses textos apresentam uma multiplicidade de vozes, as quais podem ser agrupadas em diferentes posições enunciativas (pesquisador, colegas/instituições, governo, público e o próprio jornalista). No entanto, a análise indica que a participação do governo e do público é tímida nesses textos.
\end{abstract}

Palavras-chave: Notícia de popularização da ciência. Vozes. Posições enunciativas.

\begin{abstract}
This paper presents an analysis of voices presented in science popularization (PC) news. Thirty exemplars of PC news from the BBC News and Scientific American sites were analyzed based on a Critical Discourse Analysis perspective (VAN LEEUWEN, 1996; 2008). The results show that these texts present a multiplicity of voices, which can be grouped into different enunciative standpoints (researcher, colleague, government, public and the journalist him/herself). However, the analysis indicates that the government and the public participation is timid in these texts.
\end{abstract}

Keywords: Science popularization news. Voices. Enunciative standpoints.

\section{INTRODUÇÃO}

Até meados da década de 90, a perspectiva dominante e tradicional acerca da popularização da ciência (PC) se baseava em um modelo formado por dois estágios: "primeiro, os cientistas desenvolviam conhecimento puro, genuíno; subsequentemente, versões simplificadas eram disseminadas ao público” (HILGARTNER, 1990, p. 519). Assim, na melhor das hipóteses, a PC era vista como uma "simplificação apropriada" necessária para fins educacionais de simplificar a ciência a uma audiência de não especialistas (Ibid.). Na pior das hipóteses, a PC era vista como uma "poluição" - uma

\footnotetext{
* Trabalho desenvolvido no LABLER-Laboratório de Pesquisa e Ensino de Leitura e Redação da UFSM como parte do projeto guarda-chuva Análise crítica de gêneros de artigos de popularização da ciência (PQ/CNPq número 301962/2007-3), coordenado pela professora Dr ${ }^{a}$. Désirée Motta-Roth. Versão parcial deste trabalho foi apresentada no $17^{\circ}$ Intercâmbio em Pesquisa de Linguística Aplicada (InPLA), realizado em maio de 2009, na PUC-SP.
} 
distorção da ciência realizada por jornalistas e pelo público que entende mal o que lê (Ibid.).

Essa visão reducionista recebeu críticas por parte de vários pesquisadores. Dentre eles, destacam-se Hilgartner (1990), Moirand (2003) e Myers (2003). Hilgartner (1990, p. 520) aponta que essa visão apresenta problemas conceituais e simplifica o processo de PC. Moirand (2003) complementa a ideia de Hilgartner (1990), ao argumentar que a PC não é linear, ou seja, partindo do cientista (da ciência) para o público, mas sim cíclica. Já Myers (2003, p. 266) afirma que há várias suposições que acompanham essa visão: 1) os cientistas e as instituições científicas são autoridades que decidem o que é ou não é ciência; 2) o público é uma tábula rasa em termos de conhecimento científico; 3) o conhecimento científico viaja em uma via de mão única, mais especificamente, da ciência para a sociedade; 4) o conteúdo da ciência é a informação apresentada em várias declarações escritas; e 5) a informação é simplificada e distorcida no processo popularização.

A partir de estudos na área da sociologia do conhecimento científico, a perspectiva dominante da PC tem se mostrado cada vez mais inadequada quando considerados pelo menos três aspectos (HILGARTNER, 1990, p. 522). Primeiro, o conhecimento popularizado realimenta o processo de pesquisa, uma vez que os cientistas aprendem sobre outros campos de pesquisa por meio de textos que popularizam o conhecimento científico, e isso molda suas crenças acerca do conteúdo e da conduta da ciência (Ibid.). Segundo, a simplificação é uma parte importante no trabalho científico para que haja comunicação dentro de diferentes esferas, tais como no próprio laboratório em que a pesquisa está sendo realizada e na conversa com pesquisadores de outras áreas (Ibid.). Terceiro, o conhecimento científico é produzido pela transformação coletiva das afirmações científicas, e a PC pode ser vista como uma extensão desse processo, ao invés de um processo totalmente diferente (Ibid., p. 522 e 524).

Portanto, "contemporaneamente, a PC tem sido vista como um processo político de democratização do conhecimento científico e do acesso ao debate sobre esse conhecimento, seus produtos e suas consequências" (MOTTA-ROTH et al., no prelo). A PC busca colocar a ciência no campo da participação popular (GERMANO; KULESZA, 2007, p. 20), uma vez que, atualmente, a cultura científica é vista como um direito social (CALSAMIGLIA; LÓPEZ FERRERO, 2003, p. 148).

A PC é uma atividade social rotinizada que levou à criação de vários gêneros relativamente estáveis (MYERS, 2003, p. 267). Estes foram caracterizados por Hilgartner (1990, p. 528) em um continuum que inclui desde gêneros mais próximos do contexto de produção da ciência, chamados de upstream, tais como os artigos científicos e os seminários técnicos, até gêneros dirigidos a audiências não científicas, chamados de downstream, como os livros didáticos e as notícias publicadas na mídia, gênero explorado neste trabalho.

A notícia de PC é entendida aqui como

um conjunto de manchete, lide, evento principal, nesse caso, a realização de uma nova pesquisa, o contexto, os eventos prévios, as expectativas e a avaliação do significado e da relevância da pesquisa para a vida do leitor leigo (MOREIRA; MOTTA-ROTH, 2008, p. 4). 
O objetivo desse gênero é expandir o conhecimento científico para o público em geral, transformando o conhecimento especializado em conhecimento acessível a leitores não especialistas (CALSAMIGLIA; VAN DIJK, 2004, p. 370 apud MOTTA-ROTH; LOVATO, 2009, p. 238). Portanto, a notícia de PC difere da notícia jornalística propriamente dita, uma vez que o objetivo da última é enunciar "um acontecimento (fato) contemporâneo a sua enunciação” (GUIMARÃES, 2001, p. 13) ou "um fato novo” (FRANCESCHINI, 2004, p. 148), e não a realização de uma nova pesquisa científica.

Análises prévias realizadas acerca da presença de vozes nas notícias de PC (MARCUZZO, 2008; MARCUZZO; MOTTA-ROTH, 2008; PRATES et al., 2008; MOTTA-ROTH et al., no prelo; MOTTA-ROTH; MARCUZZO, no prelo) destacam que as notícias publicadas atualmente são construídas a partir de uma multiplicidade de vozes mencionadas ao longo dos textos, as quais ajudam a promover o debate sobre ciência em exemplares desse gênero. Assim, nas notícias de PC, “o jornalista não desempenha mais o papel de mediador entre o cientista e o público: ele constrói a informação a partir de vários discursos” (BEACCO et al., 2002, p. 281). Desse modo, vários saberes entram em cena na mídia, os quais não provêm necessariamente de comunidades científicas (os próprios pesquisadores responsáveis pela pesquisa reportada ou outros colegas pesquisadores), mas de diversas procedências: “dos indivíduos afetados por problemas de várias naturezas, dos especialistas não científicos, dos leitores, das famílias, de grupos como os idosos, os adolescentes, os homens, as mulheres ou outros segmentos sociais” (NUNES, 2003, p. 45).

Neste trabalho, apresento resultados parciais de uma pesquisa em andamento ${ }^{1}$ que busca investigar em que medida as notícias de PC instauram um debate sobre descobertas científicas, a partir da análise das vozes apresentadas nesses textos. Os objetivos deste artigo são descrever e interpretar o modo como diferentes vozes são sinalizadas linguisticamente em notícias de PC. Serão apresentados dados textuais da pesquisa, a qual também prevê a realização da análise contextual dos textos, a fim de confirmar os dados levantados, adicionar validade à análise textual (BHATIA, 1993, p. 22) e coletar informações sobre o contexto de produção dos textos.

\section{METODOLOGIA}

O corpus é composto por 30 notícias de PC, sendo 15 do site BBC News (http://news.bbc.co.uk/) e 15 do site Scientific American (http://www.scientificamerican.com/). Estas foram selecionadas a partir de cinco critérios previamente definidos (MOTTA-ROTH, 2007):

a) escritos para uma audiência leiga no assunto da notícia;

b) disponibilidade na mídia eletrônica, com gratuidade e acessibilidade on-line;

c) publicação entre 2004 e 2008;

\footnotetext{
${ }^{1}$ Pesquisa de doutorado realizada no Programa de Pós-Graduação em Letras da Universidade Federal de Santa Maria (PPGL-UFSM), com bolsa da CAPES.
} 
d) temas relacionados à saúde, ao meio ambiente e à tecnologia, conforme os temas transversais apresentados nos Parâmetros Curriculares Nacionais (BRASIL, 1997a, b, c).

O corpus selecionado é apresentado nos Quadros 1 e 2.

QUADRO 1. Numeração e endereço eletrônico das notícias coletadas no site $B B C$ News.

\begin{tabular}{|l|}
\hline BBC\#1 $\underline{\text { http://news.bbc.co.uk/2/hi/health/7324555.stm }}$ \\
\hline BBC\#2 $\underline{\text { http://news.bbc.co.uk/2/hi/health/7287792.stm }}$ \\
\hline BBC\#3 $\underline{\text { http://news.bbc.co.uk/2/hi/science/nature/7324654.stm }}$ \\
\hline BBC\#4 $\underline{\text { http://news.bbc.co.uk/2/hi/science/nature/4046427.stm }}$ \\
\hline BBC\#5 $\underline{\text { http://news.bbc.co.uk/2/hi/health/7319251.stm }}$ \\
\hline BBC\#6 $\underline{\text { http://news.bbc.co.uk/2/hi/health/7443534.stm }}$ \\
\hline BBC\#7 $\underline{\text { http://news.bbc.co.uk/2/hi/health/6977423.stm }}$ \\
\hline BBC\#8 $\underline{\text { http://news.bbc.co.uk/2/hi/health/6483403.stm }}$ \\
\hline BBC\#9 $\underline{\text { http://news.bbc.co.uk/2/hi/health/6655221.stm }}$ \\
\hline BBC\#10 $\underline{\text { http://news.bbc.co.uk/2/hi/health/4632886.stm }}$ \\
\hline BBC\#11 $\underline{\text { http://news.bbc.co.uk/2/hi/health/7445606.stm }}$ \\
\hline BBC\#12 $\underline{\text { http://news.bbc.co.uk/2/hi/health/7075511.stm }}$ \\
\hline BBC\#13 $\underline{\text { http://news.bbc.co.uk/2/hi/health/7208941.stm }}$ \\
\hline BBC\#14 $\underline{\text { http://news.bbc.co.uk/2/hi/uk_news/england/7317745.stm }}$ \\
\hline BBC\#15 $\underline{\text { http://news.bbc.co.uk/2/hi/health/7380567.stm }}$ \\
\hline
\end{tabular}

QUADRO 2. Numeração e endereço eletrônico das notícias coletadas no site Scientific American.

SCIAM\#1 http://www.sciam.com/article.cfm?id=when-it-comes-to-photosynthesis-plants-performquantum-computation

SCIAM\#2 http://www.sciam.com/article.cfm?id=whole-lotta-shakin-on-ast

SCIAM\#3 http://www.scientificamerican.com/article.cfm?id=bioelectricity-versus-biofuel

SCIAM\#4 http://www.sciam.com/article.cfm?id=growing-prostate-glands-from-stem-cells

SCIAM\#5 http://www.sciam.com/article.cfm?id=mathematics-point-the-w

SCIAM\#6 http://www.sciam.com/article.cfm?id=a-tale-of-two-exoplanets-one-incredibly-hot-theother-extremely-windy

SCIAM\#7 http://www.sciam.com/article.cfm?id=genetically-modified-crops-survive-weedwhacking-herbicide

SCIAM\#8 http://www.sciam.com/article.cfm?id=is-the-out-of-africa-theory-out

SCIAM\#9 http://www.sciam.com/article.cfm?id=did-sesame-street-have-it-right

SCIAM\#10 http://www.sciam.com/article.cfm?id=that-flu-you-caught-it-ca

SCIAM\#11 http://www.sciam.com/article.cfm?id=monkey-think-robot-do

SCIAM\#12 http://www.sciam.com/article.cfm?id=new-study-links-exercise-to-longevity

SCIAM\#13 http://www.sciam.com/article.cfm?id=wireless-energy-lights-bulb-from-seven-feetaway

SCIAM\#14 http://www.sciam.com/article.cfm?id=cave-speak-did-neandertal

SCIAM\#15 http://www.sciam.com/article.cfm?id=is-human-growth-hormone-t 
Para a coleta dos dados, os textos foram lidos várias vezes a fim de que eu pudesse primeiramente entender o assunto da notícia de PC e posteriormente identificar as vozes. Para localizar os expoentes linguísticos indicativos de vozes, li cada oração do texto, concentrando-me, principalmente, nos elementos léxico-gramaticais que pudessem indicar a presença de vozes, mais especificamente, grupos nominais com núcleo de substantivos próprios indicativos de nomes de pesquisadores, instituições etc., com ou sem honoríficos, acompanhados ou não de elementos pré e pós-modificadores. Depois, busquei identificar o modo como as vozes identificadas são representadas ao longo dos textos (individualmente, coletivamente, etc.), utilizando o inventário sóciosemântico de van Leeuwen (1996; 2008). Portanto, a análise textual envolveu "a 'Identificação' de unidades de análise ou expoentes linguísticos e a 'Interpretação' semântico-discursiva desses expoentes” (MOTTA-ROTH, 2007, p. 19).

\section{AS VOZES IDENTIFICADAS NAS NOTÍCIAS DE PC}

As notícias de PC analisadas apresentam vozes identificadas com outros participantes além do jornalista que escreveu a notícia. Essas vozes marcam diferentes posições enunciativas (BEACCO et al., 2002), ou seja, o "lugar de dizer no discurso" (MUTTI; AXT, 2008, p. 353). Nos textos do corpus, além do jornalista que escreveu a notícia, foram identificadas quatro posições enunciativas diferentes, a saber:

1) o pesquisador responsável (coordenador da pesquisa ou porta-voz de um grupo) pelo estudo reportado na notícia de PC;

2) o pesquisador colega/técnico/instituição ligada ao assunto reportado;

3) o governo; e

4) o público em geral.

O jornalista apresenta comentários e opiniões de vários segmentos da sociedade que mantêm alguma relação com o tema da pesquisa reportada. Nas tabelas 1 e 2, apresento a ocorrência e a distribuição dessas posições enunciativas nos textos da $B B C$ News e da Scientific American, respectivamente.

TABELA 1. Ocorrências das posições enunciativas nos textos da BBC News.

\begin{tabular}{c|c|c|c|c|c}
\hline Texto & Pesquisador & $\begin{array}{c}\text { Pesquisador } \\
\text { colega/ } \\
\text { técnico/ } \\
\text { instituição }\end{array}$ & Governo & Público & TOTAL \\
\hline BBC\#1 & + & + & + & & 3 \\
\hline BBC\#2 & + & + & & & 2 \\
\hline BBC\#3 & + & + & & + & 3 \\
\hline BBC\#4 & + & + & + & + & 4 \\
\hline BВC\#5 & + & + & & & 2 \\
\hline BВC\#6 & + & + & & & 2 \\
\hline BBC\#7 & + & + & & & 2 \\
\hline
\end{tabular}




\begin{tabular}{c|c|c|c|c|c}
\hline BBC\#8 & + & + & & & 2 \\
\hline BBC\#9 & + & + & & & 2 \\
\hline BBC\#10 & + & + & & & 2 \\
\hline BBC\#11 & + & + & & & 2 \\
\hline BBC\#12 & + & + & & & 2 \\
\hline BBC\#13 & + & + & + & & 3 \\
\hline BBC\#14 & + & & + & & 2 \\
\hline BBC\#15 & + & + & + & & 3 \\
\hline
\end{tabular}

TABELA 2. Ocorrências das posições enunciativas nos textos da Scientific American.

\begin{tabular}{c|c|c|c|c|c}
\hline Texto & Pesquisador & $\begin{array}{c}\text { Pesquisador } \\
\text { colega/ } \\
\text { técnico/ } \\
\text { instituição }\end{array}$ & Governo & Público & TOTAL \\
\hline SCIAM\#1 & + & + & & & 1 \\
\hline SCIAM\#2 & + & + & + & & 2 \\
\hline SCIAM\#3 & + & + & + & & 3 \\
\hline SCIAM\#4 & + & + & & & 2 \\
\hline SCIAM\#5 & + & + & + & & 1 \\
\hline SCIAM\#6 & + & + & & & 1 \\
\hline SCIAM\#7 & + & + & & 2 \\
\hline SCIAM\#8 & + & + & & \\
\hline SCIAM\#9 & + & + & & & 2 \\
\hline SCIAM\#10 & + & + & & 2 \\
\hline SCIAM\#11 & + & + & & \\
\hline SCIAM\#12 & + & & & & 2 \\
\hline SCIAM\#13 & + & + & & \\
\hline SCIAM\#14 & + & + & & & 2 \\
\hline SCIAM\#15 & + & + & & & 2 \\
\hline
\end{tabular}

As Tabelas 1 e 2 mostram que todos os textos do corpus apresentam a posição enunciativa de pesquisador responsável pelo estudo. A posição de pesquisador colega/técnico/instituição ligada ao assunto reportado também é recorrente nos textos do corpus, uma vez que foi identificada em 24 de um total de 30 textos. A posição do governo aparece em oito textos, e a do público aparece em apenas dois textos. Assim, há 
cinco textos que apresentam, no mínimo, uma posição enunciativa (SCIAM\#1, SCIAM\#6, SCIAM\#7, SCIAM\#11 e SCIAM\#12), e um exemplar do corpus que apresenta até quatro posições enunciativas diferentes (BBC\#4). Quando os textos apresentam apenas as posições enunciativas de pesquisador e/ou pesquisador colega, o debate sobre descobertas científicas se restringe ao âmbito acadêmico-científico. Já quando os textos apresentam, além das posições enunciativas de pesquisador e pesquisador colega, outras posições enunciativas, o debate se amplia para os diferentes setores da sociedade que mantêm alguma relação com a pesquisa reportada, embora, muitas vezes, não sejam especialistas no assunto. A presença de várias vozes nas notícias permite um maior engajamento dos sujeitos nas conversações correntes (conversations, nos termos de Gee (2000, p. 13)) na sociedade.

Na próxima seção, apresento a análise da representação das vozes nas notícias de PC.

\section{A REPRESENTAÇÃO DAS VOZES NAS NOTÍCIAS DE PC}

A análise da representação das vozes, realizada com base em van Leeuwen (1996; 2008), revelou que, ao longo dos textos, são utilizadas diferentes estratégias para fazer referência a essas vozes. Van Leeuwen (2008) propõe várias categorias para a análise da inclusão e da exclusão dos atores sociais no discurso. No entanto, neste trabalho, apresento a análise das categorias utilizadas para a referência aos atores sociais que são efetivamente incluídos no discurso. Considerando os objetivos deste estudo, destaco as seguintes categorias propostas por van Leeuwen (1996; 2008): genericização, especificação (por assimilação/coletivização e assimilação/agregação), personalização (por diferenciação/nomeação e diferenciação/categorização/funcionalização) e impersonalização (por objetivação).

Na genericização, os atores sociais são representados como classes (VAN LEEUWEN, 1996, p. 46). A genericização pode ser realizada pelo plural sem artigo ou pelo singular com artigo definido ou indefinido (Ibid., p. 47), como no exemplo: Childbirth in the $U K$, experts stress remains very safe (BBC\#1).

$\mathrm{Na}$ especificação, os atores sociais são representados como indivíduos específicos, identificáveis (Ibid., 46). Neste trabalho, destaco dois tipos de assimilação relevantes para o presente estudo: assimilação por coletivização e assimilação por agregação.

A assimilação por coletivização representa os atores sociais como um grupo, mas sem quantificá-los, conforme o exemplo ilustra: The researchers say their next goal is to study the planets at other infrared frequencies in order to get more accurate readings and possibly learn about their atmospheres' constituents (SCIAM\#6). Já a assimilação por agregação “quantifica os grupos de participantes, tratando-os como 'estatística”" e é "frequentemente usada para regulamentar a prática e produzir uma opinião de consenso” (Ibid., p. 49). “A agregação é realizada pela presença de um quantificador definido ou indefinido, que funciona quer como numeral, quer como núcleo do grupo nominal" (Ibid.), como ilustrado pelo exemplo: More than half of Britons who took part in the "GM Nation" survey last year said GM crops should never be introduced in the UK under any circumstances (BBC\#4). 
Outra categoria de inclusão dos atores sociais é a personalização. A personalização ocorre pela diferenciação por nomeação e pela diferenciação por categorização. "A diferenciação explicitamente diferencia um ator social particular ou um grupo de atores sociais de um ator social ou grupo semelhante, criando a diferença entre o 'eu' e o ‘outro', ou entre ‘nós' e ‘eles”” (Ibid., p. 52). Na diferenciação por nomeação, os atores sociais são "representados em termos de sua identidade única, ao serem nomeados" (Ibid., p. 53). A nomeação se realiza linguisticamente por meio de nomes próprios, os quais podem ser formais (apenas o sobrenome, com ou sem honoríficos), semiformais (prenome e sobrenome) ou informais (apenas o prenome) (Ibid., p. 53). Além disso, as nomeações podem ser tituladas na forma de honoríficos ou de afiliações (Ibid.). No exemplo I wouldn't say that the transgenic varieties are able to survive better," said $\underline{\mathrm{Dr}}$ D'Hertefeldt (BBC\#3), o ator social, nesse caso, a pesquisadora que coordenou o estudo, é referido por meio de uma nomeação formal (sobrenome com o honorífico Dr.). Na diferenciação por categorização, os atores sociais são representados em termos de "identidades e funções que eles compartilham com os outros” (Ibid.). Há três formas de categorização: funcionalização, parentesco e espacialização. No entanto, tendo em vista os dados deste estudo, apresento apenas a categorização por funcionalização. A categorização por funcionalização "ocorre quando os atores sociais são referidos em termos de uma atividade, em termos de algo que eles fazem, por exemplo, uma ocupação ou um papel” (Ibid., p. 54). É tipicamente realizada por 1) um substantivo formado a partir de um verbo e composto pelos seguintes sufixos: -er, -ant, -ent, -ian, ee, -or; 2) um substantivo formado a partir de outro substantivo e composto pelos seguintes sufixos: -ist, -eer; e 3) um substantivo composto que indica ocupação, como chairperson, spokesperson, spokesman, spokeswoman. No exemplo "Essentially women who opt for a home birth face either a very successful, satisfying outcome, or a potentially disastrous one - there isn't the greyer area that you see with hospital births," says Professor Philip Steer, the editor of the BJOG. (BBC\#1), o ator social é referido pelo seu nome completo (Philip Steer), ou nomeação semiformal, nos termos de van Leeuwen (1996), pela sua profissão (professor) e pela sua ocupação (editor).

Por fim, "quando o ator social é representado por outros meios que não incluem a característica semântica 'humana', tem-se a impersonalização” (FUZER, 2008, p. 143). A impersonalização por objetivação ocorre quando os atores sociais são representados por meio de uma referência metonímica a sua ocupação ou algo associado a sua pessoa (VAN LEEUWEN, 1996, p. 59), conforme o exemplo ilustra: The new study shows that burning biomass to produce electricity rather than converting it to ethanol (made from corn kernels or the other parts of the plant, so-called cellulosic ethanol) delivers 81 percent more miles per acre of transportation in electric vehicles than ethanol burned in internal combustion, even taking into account the lifetime costs of the expensive batteries available today (SCIAM\#3). Nesse exemplo, o ator social, nesse caso, o pesquisador que realizou a pesquisa popularizada, é representado por meio da referência metonímica a sua atividade, a realização da pesquisa que está sendo popularizada na notícia de PC (The new study).

A posição enunciativa de pesquisador responsável pelo estudo é geralmente referida pelo seu nome (prenome e sobrenome com ou sem honoríficos), por exemplo, Researcher Dr Sarah Palmer (BBC\#2), space researcher Daniel Scheeres of the University of Michigan at Ann Arbor (SCIAM\#2) e pela sua função (professor, 
pesquisador, etc.). Desse modo, essa posição enunciativa é representada por meio de nomeação e funcionalização. Ao apresentar o nome e a função do pesquisador, o jornalista também menciona a instituição na qual esse pesquisador trabalha, por exemplo, Cancer Research UK (BBC\#5). A menção à função que o pesquisador exerce se constitui em um recurso de autoridade utilizado pelo jornalista para conferir credibilidade à pesquisa que está sendo popularizada (MOTTA-ROTH; LOVATO, 2009; MOTTA-ROTH, 2009), assim como a referência à instituição na qual esse pesquisador trabalha. Além disso, a posição enunciativa de pesquisador responsável pelo estudo também é mencionada por meio de coletivização, como em the staff (BBC\#15), the researchers (BBC\#2, BBC\#3, ВBC\#7, ВBC\#10, ВBC\#12, ВBC\#13, SCIAM\#3, SCIAM\#6, SCIAM\#8, SCIAM\#10 e SCIAM\#12) e team, como em The New Zealand team (BBC\#10). No entanto, a análise indica que a coletivização se manifesta mais recorrentemente no corpus pelo substantivo researchers acompanhado do artigo definido the, para designar o grupo de pesquisadores que realizaram o estudo, conforme o exemplo a seguir: The researchers report in Science that they sussed out the bug's travel plans by studying 13,000 samples of the virus collected from every continent (except Antarctica) over the past five years (SCIAM\#10).

Essa posição enunciativa também é mencionada pela genericização, por meio dos seguintes substantivos no plural: experts (BBC\#1, BBC\#6, BBC\#9 e BBC\#13), researchers (BBC\#11, BBC\#14, SCIAM\#2, SCIAM\#4, SCIAM\#5, SCIAM\#6, SCIAM\#7, SCIAM\#9, SCIAM\#11, SCIAM\#12 e SCIAM\#15) e scientists (BBC\#7, BBC\#8, BBC\#13 e BBC\#14). Nesse caso, os experts, researchers e scientists da área são tratados como uma classe sem um referente específico (Ibid.). Eles são apresentados por meio de uma genericização e são simbolicamente removidos do mundo de experiência imediata dos leitores e tratados como uma classe distante (Ibid.). Isso provoca um efeito de distanciamento entre a ciência, representada pelos pesquisadores, e o público, leitores das notícias de PC.

O pesquisador responsável pelo estudo também é mencionado por meio de uma metonímia à atividade por ele realizada, conforme já identificado anteriormente por Brasil et al. (2008), na análise-piloto dos 15 textos da BBC News. Nesse caso, a metonímia é sinalizada pelos seguintes substantivos organizados a seguir em ordem alfabética:

1) discovery (SCIAM\#14);

2) examination (SCIAM\#8);

3) project (BBC\#4);

4) research (BBC\#2, BBC\#6, BBC\#9, BBC\#10, BBC\#13 е SCIAM\#15);

5) study (BBC\#1, BBC\#6, BBC\#10, BBC\#14, SCIAM\#3, SCIAM\#6, SCIAM\#9 e SCIAM\#15); e

6) work (BBC\#7 e SCIAM\#4).

Essa posição enunciativa também é mencionada por meio de uma metonímia:

1) ao periódico em que seu estudo foi publicado (The Journal Nature Genetics (BBC\#5)); ou então 
2) ao próprio artigo publicado pelos pesquisadores que realizaram o estudo (report (BBC\#15)).

Nesse caso, é dada credibilidade às palavras escritas, que representam o conhecimento aceito pela comunidade científica publicado no formato de um artigo em um periódico da área (CALSAMIGLIA; LÓPEZ FERRERO, 2003, p. 164). A análise da referência metonímica aponta que o vocabulário utilizado faz referência ao contexto científico onde o estudo foi realizado (MOTTA-ROTH, 2009).

Essas mesmas estratégias também foram utilizadas para a referência à posição enunciativa de pesquisador colega/técnico/instituição ligada ao assunto reportado. Essa posição enunciativa pode ser referida apenas pela sua função (funcionalização), como no exemplo a seguir: A spokesman for the charity Bowel Cancer UK also welcomed the findings (BBC\#5). Nesse caso, a função desempenhada é de porta-voz de uma

instituição (Bowel Cancer UK). Geralmente, quando o pesquisador colega/técnico/instituição é representado apenas pela sua função, ele é um porta-voz de uma instituição. A posição enunciativa de pesquisador colega/técnico/instituição ligada ao assunto reportado também pode ser mencionada apenas pelo seu nome, sem menção à função da voz mencionada, como no exemplo: The Royal College of Midwives said the research was "welcome but inconclusive". "The nature of transfer means that complications are anticipated or evident. This principle applies irrespective of place of birth, whether this is at home, in a birth centre or in hospital," said Dame Karlene Davis (BBC\#1). Pode-se recuperar, pela leitura do excerto inteiro, que Dame Karlene é funcionária da Royal College of Midwives. No entanto, não é possível identificar, pela leitura do excerto ou do texto inteiro, a função dela nessa instituição.

Essa posição enunciativa também é mencionada por funcionalização e nomeação, quando são mencionados a função e o nome do pesquisador/colega/instituição em conjunto, conforme o exemplo: It's very universal. It will touch everything in materials design, says mathematician David Kinderlehrer of Carnegie Mellon University in Pittsburgh, who studies materials (SCIAM\#5). Nesse exemplo, a função é mencionada antes do nome do pesquisador colega, como um elemento pré-modificador do grupo nominal com núcleo de substantivo próprio (mathematician David Kinderlehrer).

Além disso, a posição enunciativa de pesquisador colega/técnico/instituição também é representada por meio de coletivização, conforme o exemplo: Home birth advocates say the study does not consider women who develop problems in hospital. And the deaths of babies numbered just 65, from 10,752 cases (BBC\#1). Nesse exemplo, os pesquisadores colegas/técnicos/instituições são reunidos em um grupo que defende o parto realizado em casa.

O pesquisador colega/técnico/instituição também é representado por meio de genericização, como em: Experts said the study was interesting but small and inconclusive as a result (BBC\#9). Nesse caso, a referência ao pesquisador colega/técnico/instituição foi realizada pelo substantivo expert, para conferir uma ideia de que a voz, embora não seja responsável pelo estudo, é de um/uma especialista no assunto, o que transmite mais credibilidade a essa voz para debater a pesquisa popularizada. 
Tal posição enunciativa também é representada por meio da metonímia a uma publicação de sua autoria, como em Guidance from the National Institute for Health and Clinical Excellence (NICE) in 2001 recommended donepezil, rivastigmine and galantamine should be used as standard (BBC\#9).

Já a voz do governo é geralmente transmitida no corpus por um porta-voz, que, na maioria das vezes, não tem o seu nome revelado, pois a nomeação, nesse caso, não é importante, e sim a mensagem da instituição para a qual esse porta-voz trabalha. No entanto, quando a voz do governo é apresentada por um ator social que desempenha um papel de destaque na instituição onde trabalha, por exemplo, um diretor de um órgão governamental, o secretário do meio ambiente, etc., o seu nome e sua função são apresentados. Assim, a declaração da voz do governo tem mais destaque na notícia e chama mais a atenção do leitor para a declaração dada e, consequentemente, para o assunto da notícia de PC.

Desse modo, a voz do governo é representada de três modos diferentes no corpus:

1) por objetivação (referência metonímica);

2) por funcionalização;

3) por funcionalização e nomeação; e

4) genericização.

A objetivação faz referência a uma instituição governamental, como ilustrado pelo exemplo: This year, more than 186,000 men-mostly over age 65-will be diagnosed with this form of cancer, according to the National Cancer Institute (NCI) in Bethesda, Md; some 28,000 men lose their battle with the disease each year (SCIAM\#4). Já a funcionalização faz referência ao porta-voz do governo, como no exemplo: $\underline{A}$ Department of Health spokesperson said: "Tackling the culture of harmful and binge drinking is a priority for Government and we are working with the alcohol industry and other stakeholders to implement a comprehensive strategy to tackle it" (BBC\#14). Nesse caso, o porta-voz não tem seu nome revelado, apenas sua função é mencionada, pelas razões mencionadas anteriormente.

A funcionalização e nomeação são utilizadas para a referência a uma pessoa que desempenha um papel de destaque na instituição governamental onde trabalha, como no exemplo: Dominic Harrison, deputy regional director of public health in North West, said the research confirmed the "almost daily experience" of people who saw the rising problem of young, drunk people across the region (BBC\#14). Nesse caso, foi utilizada a nomeação semiformal, incluindo nome e sobrenome.

Por fim, o governo é nomeado de forma genérica, sem menção a um determinado departamento, ministério ou uma secretaria específica, como o exemplo ilustra: Less than $2 \%$ of women currently opt for a home birth, but the government has promised all prospective mothers the choice by 2009 (BBC\#1). No entanto, pela leitura do texto BBC\#1, pode-se inferir que o substantivo government refere-se ao governo do Reino Unido, uma vez que o jornalista dá ênfase ao local de abrangência do estudo (Childbirth in the UK, experts stress, remains very safe) (MOTTA-ROTH; LOVATO, 2009, p. 259). Além disso, o jornalista faz referências a instituições do Reino Unido, como 
National Collaborating Centre for Women's and Children's Health e The Royal College of Midwives.

Já a posição enunciativa do público é mencionada em dois textos (BBC\#3 e BBC\#4). Desse modo, o público é apresentado por meio de generalização e agregação, conforme ilustrado pelos exemplos No GM crop has been found to endure so long; and critics say it shows that genetically modified organisms cannot be contained once released (BBC\#3) e More than half of Britons who took part in the "GM Nation" survey last year said GM crops should never be introduced in the UK under any circumstances (BBC\#4). No primeiro exemplo, o público não foi nomeado, sendo referenciado de forma genérica, indicada pelo substantivo “critics”. No segundo exemplo, o público foi mencionado por meio de agregação, que busca quantificar os grupos de participantes, tratando-os como um dado estatístico obtido a partir de uma pesquisa de opinião, pesquisa de marketing, etc. (VAN LEEUWEN, 2008, p. 37). Essa estratégia foi utilizada para conferir uma ideia de consenso do público sobre o assunto em debate na notícia de PC (Ibid.), nesse caso, o uso de sementes transgênicas na agricultura.

A análise da representação das vozes no corpus corrobora os dados levantados por van Leeuwen (2008, p. 45), uma vez que a funcionalização e a nomeação foram utilizadas na referência a atores sociais que têm um alto prestígio social, como os "os especialistas no assunto", aqueles responsáveis pelo estudo ou os colegas, e o "governo”, figurado pelos representantes do governo que exercem uma função de destaque nas instituições onde trabalham. Isso explica porque o nome e a função do público não são mencionados nos textos do corpus. Além disso, de acordo com Beacco et al. (2002, p. 281), a presença da posição enunciativa do público é um fenômeno recente em gêneros de PC, o que também poderia explicar sua representação ainda tímida nesses textos. Por fim, a análise da representação das vozes permitiu identificar que, principalmente, as posições enunciativas de pesquisador responsável pelo estudo e pesquisador colega são mais destacadas nos textos que o governo e o público por duas razões: 1) a recorrência em que são mencionadas ao longo dos textos; e 2) o modo como são representadas nesses textos.

\section{CONSIDERAÇÕES FINAIS}

As vozes identificadas nas notícias de PC podem ser agrupadas em quatro posições enunciativas diferentes (BEACCO et al., 2002): o pesquisador responsável pelo estudo reportado na notícia de PC; o pesquisador colega/técnico/instituição ligada ao assunto reportado; o governo; e o público em geral, além do jornalista que escreveu a notícia de PC.

No entanto, a análise da representação das vozes revela que as posições enunciativas de pesquisador e pesquisador colega/técnico/instituição recebem mais destaque nos textos pelo modo como são representadas e pela recorrência em que são mencionadas nas notícias que popularizam a ciência. Portanto, embora sejam mencionadas, as posições enunciativas do governo e do público são "mais tímidas" que a vozes do pesquisador e do pesquisador colega/técnico/instituição. Desse modo, mais poder é atribuído ao pesquisador e ao pesquisador colega/técnico/instituição no debate sobre descobertas científicas textualizado nas notícias de PC. 
Este trabalho apresenta resultados parciais de uma pesquisa em andamento. Futuros desdobramentos deste trabalho deverão incluir a análise contextual das notícias de PC e a análise detalhada da função da multiplicidade de vozes para a construção do sentido da notícia e para a constituição do gênero notícia de PC.

\section{REFERÊNCIAS}

BEACCO, J-C. et al. Science in media and social discourse: new channels of communication, new linguistic forms. Discourse Studies, v. 4, n. 3, p. 277-300, 2002.

BHATIA, V. K. Analysing genre: language use in professional settings. London: Longman, 1993.

BRASIL. Secretaria de Educação Fundamental. Parâmetros curriculares nacionais: apresentação dos temas transversais, ética. Brasília: MEC/SEF, 1997a. Disponível em: http://mecsrv04.mec.gov.br/sef/estrut2/pcn/pdf/livro081.pdf Acesso em: 12 mar. 2007.

Parâmetros curriculares nacionais: meio ambiente. Brasília: MEC/SEF, 1997b. Disponível em: http://mecsrv04.mec.gov.br/sef/estrut2/pcn/pdf/livro091.pdf Acesso em: 12 de mar. 2007.

Parâmetros curriculares nacionais: saúde. Brasília: MEC/SEF, 1997c. Disponível em: http://mecsrv04.mec.gov.br/sef/estrut2/pcn/pdf/livro092.pdf Acesso em: 12 mar. 2007.

BRASIL, A. M. de A. et al. Metáforas ideacionais em notícias de divulgação científica. In: CONGRESSO DA ASSOCIAÇÃO DE LINGUÍSTICA SISTÊMICOFUNCIONAL DA AMÉRICA LATINA (ALSFAL), 4., 2008, Florianópolis. Caderno de Resumos... Florianópolis: PPGI/CCE/UFSC, 2008, p. 58-59.

CALSAMIGLIA, H.; LÓPEZ FERRERO, C. Role and position of scientific voices: reported speech in the media. Discourse Studies, v. 5, n. 2, p. 147-173, 2003.

.; VAN DIJK, T. Popularization discourse and knowledge about the genome. Discourse Studies, v. 15, n. 4, p. 369-389, 2004.

FRANCESCHINI, F. Notícia e reportagem: sutis diferenças. Comum, v. 9, n. 22, p. 144-155, 2004.

FUZER, C. Linguagem e representação nos autos de um processo penal: como operadores do direito representam atores sociais em um sistema de gêneros. 2008. 269f. Tese (Programa de Pós-graduação em Letras) - Universidade Federal de Santa Maria, Santa Maria, 2008.

GEE, J. P. An Introduction to Discourse Analysis: theory and method. New York and London: Routledge, 2000. 
GERMANO, M. G; KULESZA, W. A. Popularização da ciência: uma revisão conceitual. Caderno Brasileiro de Ensino de Física, v. 24, n. 1, p. 7-25, 2007.

GUIMARÃES, E. O acontecimento para a grande mídia e a divulgação científica. In: GUIMARÃES, E. (Org.). Produção e circulação do conhecimento: estado, mídia, sociedade. 1 v. Campinas: Pontes Editores, 2001. p. 13-20.

HILGARTNER, S. The dominant view of popularization: conceptual problems, political uses. Social Studies of Science, v. 20, n. 3, p. 519-539, 1990.

MARCUZZO, P. A polifonia em notícias de popularização científica. Santa Maria: UFSM/PPGL, 2008. Trabalho final da disciplina teorias de gêneros discursivos (PPGLET812).

; MOTTA-ROTH, D. Polifonia e avaliação em notícias de popularização da ciência. In: Círculo de Estudos Linguísticos do Sul (CELSUL), 8., 2008, Porto Alegre. Anais... Porto Alegre: UFRGS/CELSUL, 2008. p. 1-11.

MOIRAND, S. Communicative and Cognitive Dimensions of Discourse on Science in the French Mass Media. Discourse Studies, v. 5, n. 2, p. 175-206, 2003.

MOREIRA, T. M.; MOTTA-ROTH, D. Popularização da ciência: uma visão panorâmica do Diário de Santa Maria. In: CÍRCULO DE ESTUDOS LINGUÍSTICOS DO SUL (CELSUL), 8., 2008. Porto Alegre. Anais... Porto Alegre: UFRGS/CELSUL, 2008. p.1-11.

MOTTA-ROTH, D. Análise Crítica de Gêneros com foco em artigos de popularização da ciência. Projeto de Pesquisa - Bolsa de Produtividade em Pesquisa (CNPq 2008-2011), processo no. 301962/2007-3, 2007.

Últimas descobertas! Estrutura potencial do gênero notícia de popularização da ciência. In: SIMPÓSIO INTERNACIONAL DE ESTUDOS DE GÊNEROS TEXTUAIS, 5., 2009, Caxias do Sul. Caderno de Resumos... Caxias do Sul: Educs, 2009. p. 86.

.; LOVATO, C. dos S. Organização retórica do gênero notícia de popularização da ciência: um estudo comparativo entre Português e Inglês. Linguagem em (Dis)curso, v. 9, n. 2, p. 233-271, 2009.

et al. Polifonia em notícias de popularização da ciência sob a ótica sistêmicofuncional. In: CONGRESSO DA ASSOCIAÇÃO DE LINGUÍSTICA SISTÊMICOFUNCIONAL DA AMÉRICA LATINA (ALSFAL), 4., (no prelo), Florianópolis. Anais... Florianópolis: UFSC.

.; MARCUZZO, P. Ciência na mídia: análise crítica de gênero de notícias de popularização científica. Revista Brasileira de Linguística Aplicada, Belo Horizonte. No prelo. 
MUTTI; R. M. V.; AXT, M. Para uma posição enunciativa no discurso pedagógico mediado por ambientes virtuais de aprendizagem. Interface - Comunic., Saúde, Educ., v. 12, n. 25, p. 347-61, 2008.

MYERS, G. Discourse studies of scientific popularization: questioning the boundaries. Discourse Studies, v. 5, n. 2, p. 265-279, 2003.

NUNES, J. H. A divulgação científica no jornal: ciência e cotidiano. In: GUIMARÃES, E. (Org.). Produção e circulação do conhecimento: política, ciência, divulgação. 2 v. Campinas: Pontes Editores, 2003. p. 43-61.

PRATES, N. D. et al. Organização retórica e uso de aposto em artigos de popularização da ciência. In: SEMINÁRIO DO GRUPO DE ESTUDOS LINGUÍSTICOS (GEL), 56., 2008, São José do Rio Preto. Caderno de Resumos... São José do Rio Preto: Universidade Paulista e Universidade Estadual de São Paulo, 2008.

VAN LEEUWEN, T. The Representation of Social Actors. In: CALDASCOUlThARD, C. R.; COUlTHARD, M. (Eds). Texts and Practice. London: Routledge, 1996, p. 32-70.

Discourse and Practice. Oxford: Oxford University Press, 2008. 